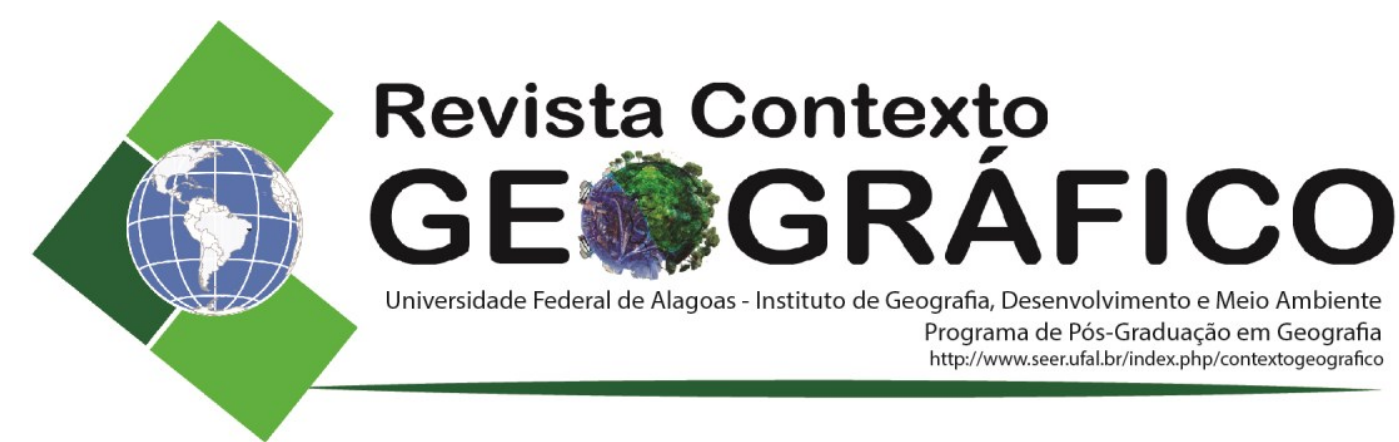

\title{
GEOGRAFIA, FORMAÇÃO ECONÔMICA E SÓCIO-ESPACIAL E O MOVIMENTO DE FUSÕES, AQUISIÇÕES E PRIVATIZAÇÕES DA DÉCADA DE 1990
}

\author{
Domingos Sávio Corrêa \\ Universidade Federal de Alagoas, Instituto de Geografia, Desenvolvimento e Meio \\ Ambiente, Maceió, AL, Brasil \\ domingos.correa@igdema.ufal.br
}

\begin{abstract}
RESUMO - O presente trabalho procura retomar a contribuição teórica de autores da Geografia ao conceito de Formação Econômica e Sócio-Espacial, associa-la ao tema das fusões e aquisições e discutir aspectos relativos à implementação das políticas neoliberais e suas consequências para a economia brasileira. Considera a relevância da categoria de formação econômica e sócio-espacial e as contribuições dos geógrafos brasileiros Milton Santos e Armen Mamigonian na discussão da temática. Ao primeiro, pela proposição da categoria de formação econômica e sócio-espacial, e ao segundo pela utilização e defesa dessa categoria de análise em sua trajetória, configurando a junção entre Geografia e Marxismo no âmbito da Geografia brasileira. Portanto, este artigo retoma pesquisa iniciada na década de 1990, e expressa o sentido geral da discussão proposta no âmbito da disciplina "Geografia da organização empresarial no Brasil e no Mundo", oferecida no Mestrado em Geografia, na linha de pesquisa "Organização do Espaço Geográfico".
\end{abstract}

Palavras-chave: Globalização; desnacionalização; neoliberalismo.

\section{GEOGRAPHY, ECONOMIC AND SOCIO-SPATIAL FORMATION AND THE MOVEMENT OF MERGERS, ACQUISITIONS AND PRIVATIZATIONS OF THE 1990}

\begin{abstract}
The present work seeks to resume the theoretical contribution of authors of geography to the concept of economic and socio-spatial formation, to associate it with the theme of mergers and acquisitions and to discuss aspects concerning the implementation of neoliberal policies and its consequences for Brazilian economy. It considers the relevance of the category of economic and socio-spatial formation and the contributions of Brazilian geographers Milton Santos and Armen Mamigonian in the discussion of the theme. The first one, by the proposition of the category of economic and socio-spatial formation, and the second by the use and defense of this category of analysis in its trajectory, configuring the junction between Geography and Marxism within the Brazilian Geography. Therefore, this article resumes research begun in the 1990 s, and expresses the general meaning of the discussion proposed within the scope of the "Geography of Business Organization in Brazil and the World", offered in the Master in Geography, in the research line "Organization of Space Geographical".
\end{abstract}

Keywords: Globalization; denationalization; neoliberalism.

\section{INTRODUÇÃO}

Este artigo retoma pesquisa iniciada na década de 1990, e expressa o sentido geral da discussão proposta no âmbito da disciplina "Geografia da organização empresarial no Brasil e no Mundo", oferecida no Mestrado em Geografia, na linha de pesquisa "Organização do Espaço Geográfico".

Nos anos da década de 1990, o Brasil viveu a exacerbação neoliberal dos processos de abertura comercial, desnacionalização, concentração e centralização de capital, considerados prejudiciais à economia nacional e redundaram naquilo que denomino como movimento de fusões, aquisições e privatizações, temática analisada na pós-graduação. O presente artigo considera a

$\begin{array}{lllll}\text { Revista Contexto Geográfico } & \text { Maceló-AL } & \text { V. 2. N.3 } & \text { Julho/2017 } & \text { P. } 01-09\end{array}$


relevância da categoria de formação econômica e sócio-espacial e as contribuições dos geógrafos brasileiros Milton Santos e Armen Mamigonian na discussão da temática. Ao primeiro, pela proposição da categoria de formação econômica e sócio-espacial, e ao segundo pela utilização e defesa dessa categoria de análise em sua trajetória, configurando a junção entre Geografia e Marxismo no âmbito da Geografia brasileira. A ambos, pela contribuição ao pensamento crítico em Geografia.

\section{A CATEGORIA DE FORMAÇÃO ECONÔMICA E SÓCIO-ESPACIAL}

Um dos aspectos a considerar sobre a trajetória do geógrafo brasileiro Milton Santos, refere-se à diversidade de sua trajetória em relação a muitos de seus contemporâneos, seja pela vivência do exílio político, estudando, lecionando e pesquisando em países europeus, africanos, latinoamericanos e outros, bem como pelas discussões estabelecidas com os diversos estudiosos da área. "A partir de 1964, exilado, Milton Santos, além de lecionar passou a estudar intensamente nas bibliotecas de Toulouse, Bordeaux e Paris a produção geográfica francesa e internacional, passando a enxergar de maneira crítica o que se fazia então" (MAMIGONIAN, A. "Milton Santos e a geografia contemporânea". Mimeo., s/d, p. 4). Além da vivência no exílio e de sua produção teórica, Milton Santos também foi reconhecido internacionalmente quando recebeu o Prêmio Vautrin Ludd, na França, em 1994.

Para Mamigonian (2004) foi após o recebimento desse prêmio, "destinado a homenagear os grandes nomes da geografia mundial", que "Milton Santos se tornou uma unanimidade para as diversas correntes que compõem a geografia humana brasileira" (s/d, pg. 1).

Por constituir a categoria "mais adequada para auxiliar na formação de uma teoria válida do espaço", Milton Santos (1977) desenvolveu a categoria de formação econômica e social, em seu texto publicado primeiramente na Revista Antipode. Nas palavras de Mamigonian (2004) este é "o mais importante texto teórico de Milton Santos", mas que não teve a merecida acolhida, tanto em The best of Antipode como no livro Geografias Pós-Modernas, de E. Soja. Ao mesmo tempo, Mamigonian (2004) ressalta que foi pequena a repercussão do trabalho nos maiores centros de pesquisa geográficos brasileiros (USP e UFRJ).

Parecendo antever o que seria debatido como "globalização", em seu livro Por uma geografia nova, Milton Santos afirma:

O mundo mundializado aí está sob nossos olhos, como um fato, embora mascarado pelas próprias condições em que foi gerado: quando a economia se baseia na insensatez, a ordem social apenas se mantém porque a ideologia se intromete; e a ordem política fica obrigada a se confundir, e isto ao infinito, com as demais instâncias de vida. O mundo 'mundial' se apresenta aos seus observadores, que são também seus personagens, como algo de incompletamente compreensível, ao menos para os indivíduos mais desarmados, que são a maioria (SANTOS, 1978, pp. 191-192).

O debate sobre a globalização dominou tanto a academia como os meios de comunicação, e Milton Santos em determinada oportunidade "reconheceu que se tratava de imperialismo e escreveu artigo em que definiu a globalização como "etapa suprema do imperialismo"”. Ainda conforme Mamigonian (2011),

\footnotetext{
"diferentemente dos ex-terceiro-mundistas do centro do sistema (Y. Lacoste e outros), Milton sempre foi muito firme nas suas opiniões, defendendo até o fim o papel progressista que a URSS havia desempenhado, o papel positivo que a China e a Índia começavam a desempenhar, mantendo intacta sua convicção socialista, contra a poderosa onda neoliberal então vigente" (2011, p. 72-73).
}

No texto analisado, Mamigonian ressalta a importância de Milton Santos e sua interpretação do processo de globalização da seguinte forma: 
É no debate sobre globalização que se percebe a radical diferença entre uma geografia combativa produzida na periferia e outra colonizada produzida no centro do sistema e para servir aos seus interesses. Em Milton há um combate radical ao imperialismo, sendo a globalização a sua etapa suprema, tão diferente da visão açucarada de D. Harvey (Condição pós-moderna), que nega e existência das relações centro-periferia. Milton teve a coragem de apontar a China e a Índia como países inseridos de forma ativa e não passiva na chamada globalização e afirmou que "não é verdade que a China esteja se tornando capitalista, podendo se utilizar do capital sem ser capitalista" (Mamigonian, 2004, p. 240).

Sem qualquer hesitação, pode-se afirmar tratar-se de fértil contribuição às discussões sobre a globalização no interior da Geografia, produzida no âmbito da Geografia Brasileira, em conformidade com a assertiva de Mamigonian (2004, p. 239), para quem Milton Santos realizou a maior aproximação entre geografia humana e marxismo, ao escrever o livro Por uma geografia nova (1978). Junto com A natureza do espaço (1996) seriam os dois "livros mais importantes sobre a teoria da geografia":

É difícil dizer qual deles terá maior efeito sobre a produção das pesquisas na ciência geográfica. Tivemos oportunidade de apontar a importância excepcional do núcleo do pensamento de Milton em Por uma geografia nova, destacando a descoberta do paradigma de formação sócio-espacial como básica para a Geografia Humana. (MAMIGONIAN, 2004, p. 239).

Ao mesmo tempo, para Mamigonian (2004), a importância do livro A Natureza do espaço não se caracterizaria por ser "uma simples continuação de Por uma geografia nova", mas "por incorporar a ideia de revolução científica e tecnológica da sociologia soviética (P. Fedoseyev, R. Richta)" e principalmente "por afastar os conceitos de forças produtivas e relações de produção" (grifo meu) pois, finalmente, "é como se Milton tivesse preferido a ideia de território à ideia de formação social, visando resolver a falta de estudos teóricos sobre o espaço." Entretanto, conforme Mamigonian (2004, p. 240): "cabe-nos perguntar se elas não são ideias que se completam".

\title{
NOTAS SOBRE AS FUSÕES, AQUISIÇÕES E PRIVATIZAÇÕES DOS ANOS 1990
}

É importante refletir sobre os efeitos da liberdade propiciada ao capital, totalmente à vontade para mover-se pelo território, sem qualquer obstáculo e muitas vezes sendo beneficiado com diversos tipos de isenções e incentivos (guerra fiscal, por exemplo). Diante do incremento da participação do capital estrangeiro em diversos setores, através de F\&A de empresas e privatizações, pode ser pensado para o caso brasileiro:

\begin{abstract}
A perda do controle nacional sobre as empresas e bancos desarticulara os mecanismos de governança e de coordenação estratégica da economia brasileira. $\mathrm{O}$ setor produtivo estatal - num país periférico e de industrialização tardia - funcionava como um provedor de externalidades positivas para o setor privado. O neoliberalismo à brasileira deixou escapar a oportunidade oferecida pelas privatizações para criar grupos nacionais - privados e públicos - dotados de poder financeiro, de capacidade competitiva nos mercados mundiais e comprometidos formalmente com as metas de desenvolvimento do país e com a geração de moeda forte (BELLUZO, in: CARNEIRO, 2002, p. 22).
\end{abstract}

Não se trata, entretanto, da simples defesa de um "nacionalismo" tosco, tão criticado ultimamente pela maioria dos meios de comunicação: quando se fala em "nacional", a menção direta refere-se à afirmação ou defesa dos interesses geoestratégicos do país, sejam tais interesses da esfera econômica, política, comercial ou outros. São evidentes os sinais de defesa dos interesses por outros países capitalistas, através de subsídios ou de incentivos às F\&A internas, em detrimento da participação de capitais estrangeiros. Não é o que 
normalmente acontece e tem ocorrido no Brasil: na maior parte dos casos, os entes econômicos têm comemorado todos os movimentos de ampliação da parcela do capital estrangeiro na geografia econômica do país. Assim é que, para Belluzo, "Quem prescinde de grupos nacionais fortes - portanto de uma estratégia de integração realmente competitiva - será simplesmente tragado pelo movimento internacional de fusões e aquisições." (Belluzzo, "Prefácio", in: CARNEIRO, R., 2002, p. 22).

De acordo com Belluzzo, a concorrência em mercados industriais contém "características que não guardam nenhuma semelhança com as superstições dos fanáticos da globalização". Pois "Até mesmo os estudiosos mais conservadores reconhecem a existência de economias de escala e de escopo, economias externas, estratégias de ocupação e diversificação dos mercados, conglomeração e acordos de cooperação. Nesse jogo só entra quem tem cacife tecnológico, poder financeiro e amparo político dos Estados Nacionais." (Belluzzo, "Prefácio", in: CARNEIRO, R., 2002, p. 23)

Carneiro (2002), critica o processo de privatização realizado no país nos anos 90, por ter suprimido da economia "um de seus principais elementos de coordenação", a saber:

\begin{abstract}
$\mathrm{O}$ investimento do setor produtivo estatal em conjunto com o gasto público tradicional operava como indutor do gasto privado, vale dizer, com investimento autônomo diante das condições correntes da demanda agregada. A privatização de vários desses segmentos mudou a natureza das suas decisões de investimento, que passaram a se pautar por critérios privados, induzidos pelo comportamento da demanda. A perda de dinamismo do crescimento daí resultante foi inevitável. (CARNEIRO, 2002, p. 40).
\end{abstract}

Conforme Carneiro (2002), a orientação geral da política econômica anticíclica orientada pelo Estado brasileiro "não se ateve exclusivamente aos gastos em infraestrutura e a setores produtores de insumos básicos", pois

Após 1976, com a desaceleração dos investimentos, ela se atrela de forma mais incisiva a uma política de sustentação de setores prioritários, como energia, agricultura e exportação, por meio de linhas de crédito subsidiadas, isenções fiscais e subsídios diretos (CARNEIRO, 2002, p. 101).

Gonçalves (1999; 2000), Miranda \& Martins (2000), Ferraz \& Iootty (2000) e Bonelli (2000), assinalam a importância e o crescimento das transações envolvendo F\&A de empresas ocorridas no Brasil e em outras regiões, a partir da década de 1990.

Gonçalves (1999; 2000) aponta as correlações entre a "globalização", a centralização do capital e a desnacionalização da economia brasileira, principalmente através do aumento de investimentos externos diretos e nas F\&A realizadas no Brasil.

Bonelli (2000) ocupa-se das F\&A no âmbito do MERCOSUL, onde observa as estratégias das empresas transnacionais. Indica que existe relação entre os processos de abertura, integração e estabilização econômica ocorridos na América Latina com o recente movimento das F\&A.

Rodrigues (1999) compara o aumento dos ingressos de investimento direto estrangeiro (de US\$ 397 milhões em 1993, para US\$1,9 bilhão em 1994, US\$9,4 bilhões em 1996 e US\$ 17 bilhões em 1997) com estimativas da SOBEET que mostram o crescimento do Brasil, "na ponta vendedora", em relação ao volume de transações internacionais, da seguinte ordem: de US\$ 1,3 bilhão em 1994, US\$ 2,1 bilhões em 1995 e US\$ 4 bilhões em 1996, o que teria determinado o aumento da participação das empresas estrangeiras, no início dos anos 1990, nas F\&A nos setores de autopeças e alimentos/bebidas (p. 5).

Lodi (1999) refere-se ao "cenário brasileiro" das F\&A, apresentando as biografias de algumas empresas familiares, tanto internacionais quanto nacionais.

Gonçalves (2000), entende que o Brasil sempre se caracterizou por possuir "uma das economias mais abertas do mundo", assim como ocorrera sempre uma inserção passiva do país na 
economia internacional, ideia que nos parece polêmica, pois parece retirar do processo histórico a dialética do desenvolvimento econômico e industrial do país, conforme analisado por Rangel (1999), através de seu conceito de dualidade da economia brasileira, em relação a um ciclo de desenvolvimento externo (Kondratieff) e um ciclo de desenvolvimento interno, de curta duração (Juglar). Esta é uma perspectiva importante para a plena compreensão do desenvolvimento econômico brasileiro. Entretanto, Gonçalves procura caracterizar definitivamente o Brasil da década de 1990, com a imposição da abertura econômica, que causou maior dependência de fluxos financeiros internacionais, crescimento do endividamento interno e externo, diminuição das taxas do PIB, aumento dos índices de desemprego, entre outras consequências do assim chamado processo de modernização econômica. A constatação mais eloquente, conforme Gonçalves refere-se ao "mais amplo e profundo processo de desnacionalização da história econômica do país". O autor afirma ter aumentado a participação de estrangeiros no valor bruto da produção, de 13,5\% em 1995 para 24,6\% em 1999, além do aumento da "participação estrangeira no valor das vendas das 550 maiores empresas", de 33,3\% em 1995 para 43,5\% em 1998. Entre as 500 maiores empresas privadas no Brasil, 144 seriam estrangeiras em 1995, número que aumentou para $170 \mathrm{em} 1997$ e saltou para $209 \mathrm{em} \mathrm{1998.} \mathrm{O} \mathrm{autor} \mathrm{afirma} \mathrm{que} \mathrm{teria}$ ocorrido um verdadeiro "salto quântico" na desnacionalização da economia brasileira a partir de 1995. Mas não ocorreu apenas isso, pois também houve queda da "participação das empresas de capital privado nacional", de 44\% em 1994 para 39,4\% em 1998, além da queda de "participação das empresas estatais de 24\% em 1994 para 17,1\% em 1998", concluindo que o processo de desnacionalização seria "inusitado na história da economia brasileira", com o enfraquecimento do capital nacional, acompanhado por concentração de capital onde os grupos estrangeiros passaram a ter maior importância relativa.

A entrada de capital estrangeiro encontra-se associada ao ambiente de instabilidade e crise econômica do País, com "aumento da vulnerabilidade externa, desemprego, degradação das contas públicas e taxas decrescentes e medíocres de investimento", ainda conforme Gonçalves (2000), que aponta quatro fatores para o aumento do capital estrangeiro no Brasil: 1) crescimento dos fluxos de investimento direto; 2) F\&A em escala global; 3) mudanças no aspecto regulatório (liberalização e desregulamentação), além das privatizações (4).

Assim, F\&A e privatizações não ocorreram isoladamente ou à margem de decisões e políticas de governos democraticamente eleitos, cujos pressupostos, entretanto, não foram os mesmos em todos os países.

A tendência de crescimento de IED está associada ao grande aumento das F\&A em todo o mundo. O autor indica o crescimento do IED de um montante por volta de US\$ 329 bilhões, no ano de 1995, para US\$ 644 bilhões em 1998, da mesma forma que também houve aumento das F\&A transfronteiriças, de US\$ 141 bilhões em 1995 para US\$ 411 bilhões no ano de 1998. Já no Brasil, no mesmo período, o crescimento das F\&A também se revelou extremamente significativo, saltando de US\$ 1 bilhão (1995), para valores superiores a US\$ 21 bilhões (1998). Neste processo, as privatizações ocorridas no Brasil foram responsáveis por aproximadamente " $25 \%$ do valor total do ingresso bruto de IED no período 1995-1999." O autor conclui pela "inserção passiva do país na economia mundial", representada pela desnacionalização e concentração de capital.

Gonçalves (2000), assinala diferenças entre o movimento de F\&A ocorrido nos anos da década de 1980 e o posterior movimento dos anos 90 . Na década de 80 a característica preponderante seria a das aquisições hostis, sem qualquer tipo de negociação entre as partes, a transação resultando de uma "ação unilateral por parte de um agente econômico"; já na década de 1990 as transações teriam sido caracterizadas por "orientação de natureza estratégica e de longo prazo", cuja diferença principal refere-se ao pagamento dos negócios, realizados à vista nos anos 1980, enquanto nos anos 1990 foram realizados principalmente através de ações. Entretanto, no período recente, surgiram tentativas de aquisições hostis.

O movimento de F\&A disseminou-se pela economia mundial e fariam parte do período de globalização da economia, "caracterizado pela aceleração dos fluxos internacionais de bens, serviços, tecnologia e capital" (Ferraz \& Iootty, 2000, p. 39), enquanto para Lacerda (1999, p. 
8), o processo de globalização ainda não teria sido suficientemente compreendido e conforme Batista Jr. (1997, p. 7) não seria mais que uma "falsa novidade".

Ferraz e Iootty (2000) consideram "indiscutível a importância econômica do processo de F\&A em curso nas principais economias do planeta", de forma que o crescimento desse processo foi "exponencial ao longo da última década", ressaltando em suas análises a "aceleração dos fluxos internacionais de bens, serviços, tecnologia e capital", além do "intenso processo de transformações tecnológicas e mudanças nos regimes nacionais de incentivos e regulação, na direção da liberalização econômica". Em sua análise, as F\&A resultariam de estratégias empresariais "que buscam impor padrões de inovação e consumo e explorar mercados com amplitude global, antecipando ou em resposta às mudanças no ambiente competitivo onde operam", consistindo um tipo de empresa "que cresce além das fronteiras nacionais".

Além de pioneiro nos estudos de fusões e aquisições, o artigo de J. C. Miranda e L. Martins apresenta metodologia para analisar os dados divulgados pelas empresas de consultoria em F\&A, como KPMG e Securities Data, cujos dados foram utilizados pelos autores em seu artigo.

Em determinados momentos, as fusões e aquisições são intensificadas em um processo resultante do movimento de acumulação e expansão do capital relacionado às crises econômicas e busca pela ampliação da taxa de lucros.

\begin{abstract}
A fase final da evolução do monopólio do capital ocorre quando se formam combinações com o objetivo consciente de acabar com a concorrência. Essa fase só é atingida numa base relativamente alta de centralização que, reduzindo o número de empresas em determinado setor de produção, torna a concorrência cada vez mais severa e perigosa para os sobreviventes. A concorrência tende a se transformar numa luta mortal que não beneficia ninguém. Quando isso ocorre, o terreno para o movimento de combinação está preparado (SWEEZY, 1962, p. 307).
\end{abstract}

Ao mesmo tempo, consideramos, de acordo com Lênin (2000), "O enorme desenvolvimento da indústria, e o processo de concentração extremamente rápido da produção, em empresas cada vez mais importantes, constituem uma das características mais marcantes do capitalismo" (p. 16). Este autor, no início do século $X X$, produziu a mais profunda análise referente ao desenvolvimento do monopólio e, além disso, desenvolveu sua abordagem sobre o imperialismo após as importantes contribuições de John Atkinson Hobson e Rudolf Hilferding.

A partir dos anos 1990, especificamente no caso brasileiro, as combinações de capital foram crescentes, motivadas pelas medidas econômicas adotadas na década, através de políticas que terminaram por implementar a abertura econômica, as privatizações e a intensificação do investimento estrangeiro e de seus efeitos em detrimento do capital nacional. Neste processo, uma parcela significativa dos empresários nacionais praticamente desapareceu ou migrou para outros setores de atuação. As medidas adotadas decorreram das recomendações no contexto do Consenso de Washington, para minimizar os efeitos da crise econômica.

Chesnais (1996) analisando o crescimento do Investimento Externo Direto demonstra como ele superou "os investimentos criadores de novas capacidades" através das F\&A nos países da tríade (EUA, Alemanha e Japão):

Em meados da década de 70, diversos tipos de incentivos e de restrições impulsionaram as empresas a optar por aquisições/fusões, num momento de farta disponibilidade e contando com novos instrumentos criados no contexto da globalização financeira (Chesnais, 1996, p. 64).

Enquanto entre os objetivos principais de uma aquisição/fusão consistiam

Em pegar uma parcela do mercado, especialmente quando acompanhada pela aquisição de marcas comerciais, de redes de distribuição e de clientes cativos. É bem compreensível que - no duplo contexto de uma conjuntura econômica mundial marcada por muita incerteza e instabilidade, mesmo nos períodos de 
retomada, e de intensificação da concorrência, devido à abertura dos oligopólios nacionais e, ao mesmo tempo, ao reduzido crescimento da demanda em vários setores do mercado - as aquisições/fusões tenham se beneficiado de forte preferência (Chesnais, 1996, p. 64).

Para Chesnais (1996), a partir do final da década de 1970, houve uma convergência "para detonar um grande movimento de investimento internacional cruzado, dominado pelas aquisições/fusões". Com esse movimento e com o processo de concentração/centralização, foi inevitável sua amplificação e aceleração.

No conjunto da década de 1990, conforme Santos (2000), os "últimos anos do século XX foram emblemáticos, porque neles se realizaram grandes concentrações, grandes fusões, tanto na órbita da produção como na das finanças e da informação" (p. 46). As privatizações, para Santos (2000) seriam decorrentes de um "discurso" imposto para convencer a sociedade da necessidade de "haver menos Estado" tendo por base "o fato de que os condutores da globalização" necessitariam "de um Estado flexível a seus interesses". Em sua análise, as privatizações seriam o exemplo da extrema voracidade do capital, com crescentes exigências. Ao mesmo tempo, "a instalação desses capitais globalizados supõe que o território se adapte às suas necessidades de fluidez, investindo pesadamente para alterar a geografia das regiões escolhidas". Assim, para Milton Santos,

o Estado acaba por ter menos recursos para tudo o que é social, sobretudo no caso das privatizações caricatas, como no modelo brasileiro, que financia as empresas estrangeiras candidatas à compra do capital social nacional. Não é que o Estado se ausente ou se torne menor. Ele apenas se omite quanto ao interesse das populações e se torna mais forte, mais ágil, mais presente, ao serviço da economia dominante (SANTOS, 2000, p. 66).

Enquanto para Mamigonian,

A tendência das gigantescas fusões de hoje em dia assinalam a possibilidade do aparecimento dos primeiros cartéis globais, como nas previsões da existência provável de cinco ou seis grandes operadoras de telecomunicações em 2005-2010, ou de cinco ou seis grandes montadoras automobilísticas, etc. A "globalização" como ideologia que se vende e se impõe aos povos oprimidos é basicamente o projeto econômico-político americano de liderar o ultra-imperialismo futuro. E isto nos interessa? (2004, vol. II, p. 145).

As F\&A foram consideradas características do processo de "globalização"; assim, se a década de 1980, para alguns, ficou conhecida como a "década perdida", característica de uma "inserção passiva" do Brasil no conjunto da economia mundial, conforme expressão de Gonçalves (1999) os anos da década de 1990, para outros, entraria para a história como a "década prostituída". Em análise sobre os anos 1990, Paulo N. Batista Jr. afirma: “(...) para os interesses financeiros externos e internos, a década de 90 não foi nada perdida (...) O ex-secretário da Receita Federal, Osíris Lopes Filho, alinha-se àqueles que consideram a expressão 'década perdida' inadequada para os anos 90. Para ele, o que tivemos foi uma 'década prostituída'. A expressão é violenta (...) mas não é de todo descabida. Nesses anos, venderam o país com grande afinco e entusiasmo. A desnacionalização avançou perigosamente. $\mathrm{E}$ as políticas macroeconômicas adotadas deixaram o Brasil à mercê do hospício em autogestão vulgarmente conhecido como "sistema financeiro internacional"". ("A década prostituída". Folha de S. Paulo, Dinheiro, 30/12/1999). Para Luciano Coutinho "Cinco anos de câmbio sobrevalorizado, juros proibitivos, abertura comercial gratuita e privatização sem estratégia produziram um movimento sem precedentes de desnacionalização e de encolhimento dos grupos econômicos nacionais (...) O Brasil, após marcar passo nos anos 80, retrocedeu nos 90. Enquanto isso, algumas economias asiáticas (notadamente a Coréia do Sul, mas também a China e Taiwan) construíram grandes grupos econômicos - de porte e atuação globais (grifo nosso), com crescente 
capacitação técnica na fronteira das tecnologias da informação e com afirmação de marcas mundiais." ("Por que "multinacionais' brasileiras?". Folha de S. Paulo, Dinheiro, 27/02/2000.

Em outra oportunidade, Osíris Lopes $\mathrm{F}^{0}$ escreveu: "A década prostituída, a dos anos 1990, foi de padecimento (...). As funções governamentais limitaram-se à formulação de políticas entreguistas e ineficazes, transformando o país em território propício à rapina, pelos capitais estrangeiros", com o apoio explícito das forças políticas dominantes e setores sociais descompromissados com o interesse nacional e a implementação de um projeto de desenvolvimento soberano para o Brasil.

\section{REFERÊNCIAS}

BATISTA, P. N. "O Consenso de Washington - a visão neoliberal dos problemas latino-americanos". Consulta Popular, cartilha ${ }^{\circ} 7$, novembro/1999.

BATISTA JR., P. N. ““Globalização’ e administração tributária”. Princípios, set./1997.

BIONDI, Aloysio. O Brasil Privatizado - um balanço do desmonte do Estado. São Paulo: Editora da Fundação Perseu Abramo, 1999.

BONELLI, Régis. "Fusões e aquisições no Mercosul". In: Veiga, Pedro da Motta (org.). O Brasil e os desafios da globalização. Rio de Janeiro: SOBEET e Relume Dumará, 2000.

$\overline{\mathrm{abril} / 2000 \text {. }}$

.Fusões e aquisições no Mercosul”. In: Textos para Discussão, no 718, IPEA, Brasília,

CARNEIRO, R. Desenvolvimento em crise - a economia brasileira no último quartel do século $\mathbf{X X}$. São Paulo: Editora Unesp, IE Unicamp - Unicamp, 2002.

CHESNAIS, François. A mundialização do capital. São Paulo: Xamã, 1996.

GONÇALVES, R. Globalização e desnacionalização. São Paulo: Paz e Terra, 1999.

. "Centralização do capital em escala global e a desnacionalização da economia brasileira". In: VEIGA, Pedro da Motta (org.). O Brasil e os desafios da globalização. Rio de Janeiro: SOBEET e Relume Dumará, 2000.

LACERDA, A. C. de. O impacto da globalização na economia brasileira. São Paulo: Contexto, 1999.

LÊNIN, V. I. O imperialismo, fase superior do capitalismo. São Paulo: Editora Centauro, 2000.

MAMIGONIAN, Armen. "Notas sobre os frigoríficos do Brasil Central Pecuário". Boletim Paulista de Geografia, S. Paulo, n 51, p. 7-14, jun. 1976.

."Milton Santos: sartreano e terceiro mundista". In: SILVA, M. A. da (Org.) 10 anos sem Milton Santos. Salvador: Alba, 2011, pp. 72-73.

Estudos de geografia econômica e de pensamento geográfico. 264 pgs. Tese (Livre docência). São Paulo: Faculdade de Filosofia, Letras e Ciências Humanas/USP, 2004.

MAMigOnian, A. e REGO, J. M. O pensamento de Ignácio Rangel. S. Paulo: Editora 34, 1998.

MCCRAW, T. K. (Org.). Alfred Chandler: ensaios para uma teoria histórica da grande empresa. Rio de Janeiro: Editora Fundação Getúlio Vargas, 1998.

MIRANDA, J. C. \& MARTINS, L. "Fusões e aquisições de empresas no Brasil", Economia e Sociedade, Campinas (14): 67-88, jun. 2000.

PIZZO, M. do R. "Rangel e a concessão de serviços públicos à iniciativa privada". In: Mamigonian, A. O Pensamento de Ignácio Rangel. Florianópolis: UFSC/PPGG, 1997.

POCHMANN, M. A década dos mitos - o novo modelo econômico e a crise do trabalho no Brasil. São Paulo: Editora Contexto, 2001.

RANGEL, I. Dualidade básica da economia brasileira. São Paulo: Bienal, 1999, 2ª edição. 
pensamento de Ignácio Rangel. S. Paulo: Editora 34, 1998, pgs. 139-170.

Economia Brasileira Contemporânea. São Paulo: Bienal, 1987.

Economia: milagre e anti-milagre. Rio de Janeiro: Jorge Zahar, 1985.

setembro/1983

“Esta crise não se administra”. Revista de Economia Política, vol. 3, n 3, julho-

RODRIGUES, R. I. "Empresas estrangeiras e fusões e aquisições: os casos dos ramos de autopeças e de alimentação/bebidas em meados dos anos 90”. In Textos para discussão, nº 622, IPEA, Brasília, 1999.

SANTOS, M. Por uma outra globalização. Rio de Janeiro, São Paulo: Record, 2000.

"Sociedade e Espaço: A Formação Social como Teoria e como Método", Boletim Paulista de Geografia, S. Paulo, nº 54, p. 81-99, jun. 1977.

VEIGA, P. da M. (org.). O Brasil e os desafios da globalização. Rio de Janeiro: SOBEET e Relume Dumará, 2000.

VIEGAS, C A. dos S. Fusões e aquisições na indústria de alimentos e bebidas no Brasil: análise dos efeitos nos preços ao consumidor. Tese (Doutorado) - Universidade de São Paulo, 2006. 